\title{
10 Anton Pannekoek as a Pioneer in the Sociology of Knowledge
}

\author{
Bart Karstens
}

\begin{abstract}
Thirty years after the publication of Pannekoek's 1953 paper on the history of the discovery of Neptune, it was cited as an early forerunner of the strong programme in the Sociology of Scientific Knowledge. This recognition, however, was achieved by laying Pannekoek's paper on a Procrustean bed. On close inspection we find that Pannekoek's approach to history accords best with Merton's sociology of knowledge. Thus, Pannekoek gained a reputation as an important innovator in historiography of science for the wrong reasons. This paper offers a much-needed correction, which facilitates a more precise evaluation of the innovative aspects of Pannekoek's historical work, especially with respect to the effect of external factors on the course of science.
\end{abstract}

Keywords: Anton Pannekoek, sociology of science, strong programme, Robert K. Merton, discovery of Neptune

\section{Introduction}

The activities of Anton Pannekoek in the fields of social theory and astronomy are well known and the subject of most contributions to this volume. Perhaps less well known are his efforts in the history of science. Pannekoek devoted two books to the history of astronomy. Early in his career he published De Wonderbouw der Wereld: De grondslagen van ons sterrekundig wereldbeeld populair uiteengezet (1916) and after his retirement he wrote De Groei van ons Wereldbeeld: Een geschiedenis van de sterrekunde (1951), which was translated into English as A History of Astronomy (1961).

Tai, Chaokang, Bart van der Steen, and Jeroen van Dongen (eds), Anton Pannekoek: Ways of Viewing Science and Society. Amsterdam, Amsterdam University Press 2019 DOI: $10.5117 / 9789462984349+C H 10$ 
While Wonderbouw contains an exposition of the state of the art of astronomical knowledge at the time when it was published, offering only occasional historical perspectives, De Groei van Ons Wereldbeeld is a truly historical work, tracing the history of astronomy from Antiquity to the present. From this book, Pannekoek lifted a paper on the discovery of Neptune, which was published in Centaurus in 1953. Interestingly this paper was taken up from the 1980 on onwards by scholars in the Sociology of Scientific Knowledge (henceforth referred to as SSK) as a splendid early example of how to properly explain the history of science. Pannekoek's interpretation of the discovery of Neptune even made it into a $2004 \mathrm{Handbook}$ of Epistemology, as David Bloor in his contribution on SSK cited Pannekoek's study as one of the prime examples in support of the SSK approach. ${ }^{1}$ This is a remarkable feat, given that Pannekoek was not a professional scholar in the History and Philosophy of Science.

It is even more remarkable that Pannekoek's paper was taken up by a group of scholars that defend a radical position in the sociology of knowledge, which is identified as the strong programme. The leading idea of the strong programme is that the rejection and acceptance of all claims to knowledge (i.e. what we come to hold as true or false about the world) is always ultimately determined by social factors. This idea dates from the mid-1970s and represented a further step in the development of epistemological relativism. ${ }^{2}$ Thomas Kuhn and others had already rejected the idea that the structure of the world is just there, waiting to be discovered, and hence that nature itself is the sole referee of the correctness of our theories about nature.

Yet, to let the human element play a decisive role in all of science was a radical step to make. Other positions in the sociology of knowledge exist as well, granting an important role to the notion of science as a social process, because science after all is a human endeavour, but at the same time acknowledging the importance of nature in our theories of the world too. One can, for example, argue that society to a large extent decides which topics scientists will investigate. The direction of research is then determined by social factors, but the content of it does not have to be, since one can take the view that scientific research roughly proceeds in the same manner

1 Bloor 2004. The Handbook of Epistemology, together with The Oxford Handbook of Epistemol$o g y$, is one of two of the most recent handbooks of epistemology. Its goal is to provide an overview of the historical roots and systematic development of the theory of knowledge. It contains 28 entries written by a variety of scholars. Bloor's 'Sociology of Scientific Knowledge' is one of these entries.

$2 \quad$ A key text is Bloor 1976. 
everywhere. In such approaches the social only weakly determines scientific outcomes. ${ }^{3}$

Overall, Pannekoek's historiography is marked by optimism and progressivism. He makes it abundantly clear that the historical development of science should be interpreted as a logical succession of stages towards uncovering the truth. Next stages build on earlier ones and in this way our understanding of the world gradually grows. Now this perspective on the history of science cannot be squared with SSK's epistemological relativism at all, given that the traditional notion of truth no longer holds in the strong programme. To find Pannekoek hailed as a pioneer of SSK is thus surprising. Moreover, while there were weak programmes in the sociology of science in the 1950s, no one was already pursuing something as radical as SSK scholars later started to do. So, what is going on here? Has Pannekoek's account of the discovery of Neptune perhaps been richly interpreted by SSK scholars? Has he simply been misread? Or did Pannekoek's paper indeed contain the contours of a new approach to the history of science, perhaps rooted in the special brand of Marxism he had developed?

The present paper aims to provide an answer to these questions. It is structured as follows. In the first section I summarize the interpretation offered by Pannekoek in his 1953 paper. Then I show how this paper was cited by SSK scholars, respectively Barry Barnes (1982), Steven Shapin (1982), Simon Schaffer (1986), and finally David Bloor (2004). While these authors are very sympathetic towards Pannekoek, I will argue that they nonetheless do not do full justice to his views. Because Pannekoek clearly grants an important role to social factors in the discovery process of Neptune I then proceed in section three to consider whether his account befits other sociological approaches. I will argue that this is indeed the case and that his historical work best matches Merton's sociology of science. In section four I conclude by maintaining that Pannekoek can be seen as a forerunner, not of SSK, but of other forms of contextualism in the historiography of science. In 1953, it was still rare to grant such an important role to external factors in historical explanations. More specifically, Pannekoek's treatment of competition between countries was innovative because he was one of the first to take the discussion of such competition beyond mere priority issues, allowing for a richer and more complex treatment of the subject.

3 Historians of science may have remained agnostic about the strong programme but Jan Golinski (2005) shows that it has nonetheless set the agenda in terms of research topics of much historical work in the past few decades. For the agnosticism of historians, see Shapin 1992. 


\section{'The Discovery of Neptune' (1953)}

In 1781, William Herschel discovered the planet Uranus. In the decades after this discovery, observations registered perturbations to the expected orbit of Uranus, as predicted by Newton's theory of gravity. This was not taken as a serious problem for Newton's theory but led to the idea that there must be another mass present causing the perturbations, most likely another

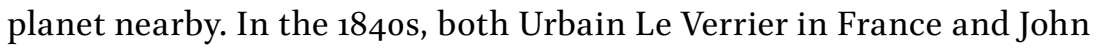
Couch Adams in England started to calculate the position of the planet. Independently, they arrived at the same result. This then still required confirmation by observation. The French turned out to come first here as a Berlin observatory confirmed Le Verrier's calculation in September 1845 . As a consequence, the credit for the discovery of Neptune went to France.

The first part of Pannekoek's account of this episode offers an explanation for the fact that the English lost the priority dispute. After all, Herschel had also discovered Uranus and the British were better equipped with observatories than the French. Pannekoek explains the difference in pace, in making the discovery 'complete', with respect to differences in the social structure of England and France. In the 1840s, the rising bourgeoisie in France still had to fight the authority of Church and nobility. Science, according to Pannekoek, was an important asset in this fight because it showed people that another world order, governed by scientific principles, was possible. The fact that one could predict the structure of the universe (i.e. the existence of a planet) based on a scientific theory (Newton's Law of Universal Gravitation) was a splendid proof of the power of science. This explains the efforts of the French to make the discovery known to the public. Le Verrier also published a book of more than 200 pages, simultaneously showing the difficulty of the problem and the skill required to overcome it. According to Pannekoek, this way of publishing the result of the discovery of the new planet also had the purpose of enhancing the prestige of science. ${ }^{4}$

In contrast, Adams only wrote a small paper of $3^{1}$ pages in which he presented his calculations of the orbit of Neptune. In this paper, Adams clearly indicated a number of uncertainties in his calculations. Pannekoek saw this as an expression of Adams' modesty (which he praises), but also of a lack of sense of urgency to work on these uncertainties and match the calculations with observation. Pannekoek explains this as follows: in England no battle of the bourgeoisie against Church and nobility was needed

4 In a recent article, James McAllister (2015) called this 'the rhetoric of effort': painstaking labour (extreme carefulness, avoidance of error, etc.) lends credibility to a scientific result. 
anymore. The reign of Cromwell had broken the self-evident government of the royals. Gradually, this led to legal fortification of the position of the bourgeoisie: 'after many stages of advance, the bourgeoisie had already reached a situation in which the Reform Act of $183^{2}$ and the repeal of the Corn Laws in 1846 left it as virtually the supreme power in the land'. ${ }^{5}$ In the Netherlands and France this only happened in the revolutionary year 1848, and in Italy and Germany even later because these countries still needed to become unified states.

Because no social battle was needed anymore in England, using the weapon of science was not an urgent matter. This, according to Pannekoek, explains the open expression of uncertainties and the slower pace of doing research in England compared to France. Social factors thus played a role in determining the speed of scientific development. Pannekoek was forced to positively evaluate the role of bourgeoisie in this period. Although the bourgeoisie came to oppress the working class later in the nineteenth century, and should thus be overthrown, it had also played a crucial role in overthrowing the traditional institutions of power. For a Marxist this was not a common line of reasoning. ${ }^{6}$ It also led Pannekoek to defend the, at first sight, odd position that science in the more advanced England (in terms of social structure) prospered less than in France. The second part of the story, in which the United States enters the picture, will make this more understandable.

The first part of the story has not gone uncontested in historiography of science. Robert W. Smith questions Pannekoek's idea of the 'calm indifference' with which Adams's calculations and the loss of the priority dispute were met in Britain. Smith shows that the events surrounding the discovery of Neptune did arouse huge passions. The English had thought that the discovery of Neptune should naturally be awarded to them and regretted missing it very much. This even led to serious damage in the prestige of a number of English scientists, most notably the Astronomer Royal, George Biddell Airy. Smith also attributes the French winning of the priority dispute to social factors, but in his account internal social struggles slowed the British down. There were fights over financial budget between universities (and other research institutes). On the one hand, this made people cautious in making claims of scientific breakthroughs. One had to be certain, because wrongful claims would jeopardize the reputation of a scientist as well as

5 Pannekoek 1953, 130.

6 More on Pannekoek's anomalous Marxism and the history of science follows in the section below. 
the institution to which he was affiliated, and this could lead to a decrease in financial resources. On the other hand, competition also meant a slower exchange of ideas, in the case of the discovery of Neptune for example between Cambridge University and the Greenwich observatory. ${ }^{7}$

Others have sought more personal reasons for the hampering communication. According to William Sheehan and Steven Turber, the modesty of Adams and his habit of keeping things for himself have to be attributed to an autistic mental disorder. The discovery of the new planet required the ability to fully concentrate on a problem, paired with the mathematical skill to solve it, and social skills to discuss calculations and cooperate with astronomic observers. Adams had the first ability but lacked to second, and that is why England failed to win the priority dispute. ${ }^{8}$

The latter interpretation is hard to check against the historical record. Smith, however, has at least convincingly proved that the discovery of Neptune aroused much passion in England, which is already enough to seriously question Pannekoek's explanatory scheme. Pannekoek can perhaps be credited for opening the door to more intricate explanations of priority disputes between nation states, because he was a pioneer in paying attention to differences in social structure. ${ }^{9}$ Yet, it is highly unlikely that his account can stand up to scrutiny. For the present purposes this does not matter very much, because I am investigating how Pannekoek's scheme of explanation orbited into the SSK publication trail. If his interpretation of the discovery of Neptune does indeed contain major flaws, this even more begs an explanation of the later positive citation of Pannekoek's paper by SSK scholars.

For these purposes the second part of the story is actually the most interesting one. Le Verrier and Adams had calculated roughly the same orbit for Neptune and the observation in Berlin matched this calculation. However, two Americans, Sears Cook Walker and Benjamin Peirce, noticed that earlier observations of presumably the same heavenly body could

$7 \quad$ Smith 1989.

8 Sheehan and Thurber 2007.

9 Pannekoek also considers cooperation between England and France, which makes the story even more complex. Le Verrier and Adams became friends and in 1848 they were honoured together by the Royal Astronomical Society when Le Verrier visited England. According to Pannekoek $(1953,133)$ their simultaneous calculation had demonstrated the power of science because it was proof that the discovery was not just a chance happening but something more profound. He again praised Adams's modesty and lack of ambition, which according to him made a friendship with Le Verrier possible 'in a situation that contained all the elements necessary for a fierce personal conflict'. 
not be fitted into the orbit calculated by Le Verrier and Adams. A later observation, after $185^{\circ}$, also diverged from the calculated pattern. Walker and Peirce proceeded to calculate another orbit that had to be empirically adequate with respect to all observed positions. This orbit turned out to be significantly smaller than the one calculated by Le Verrier and Adams.

Now, there were thus two ways of accounting for the same data. Perhaps the observations dating from earlier days did not refer to the same planet? Peirce initially suggested that this might be possible and hence that the two orbits referred to two different planets. The French however rejected this possibility. According to Pannekoek, this was because their whole publication strategy, including outreach to the general public, would then fail: the predictive power of science allowed for only one planet to be discovered. The English joined the French. Both Herschel and Struve initially saw the competing American calculation as an unjustified, wild attack. This attitude led Europeans to ignore for a while the further calculations produced by the Americans. Yet, these calculations demonstrated beyond reasonable doubt that data of Neptune obtained between 1800 and $185^{\circ}$ fitted both orbit calculations (Figure 10.1). However, only the smaller orbit could account for the additional data. Because of the similarity during the period 1800-1850 the existence of two planets had to be ruled out. The Europeans could only save their one planet theory by admitting their calculations had been wrong. ${ }^{10}$

This was not an easy matter. Pannekoek again explains the lack of openness to the American critique with reference to differences in social structure. Both in England and in France, the bourgeoisie could not yet deal with a blow to their reputation. Social embarrassment in his view blocked an open discussion. Pannekoek approvingly quotes the Leiden astronomer Frederik Kaiser who complained in 1851 that in the United States people did not have to claim so hard that they had discovered something and

10 Walker and Peirce calculated what we now think is the correct orbit of Neptune. Thus Le Verrier and Adams had calculated the same erroneous orbit independently from each other. This resembles another occasion in the history of science in which both Galileo and Descartes (together with Isaac Beeckman) independently arrived at a mistaken formula of free fall, namely with speed as a function of traversed distance. Only Galileo managed to change his mind and calculate the speed of an object in free fall as a function of time elapsed. Alexandre Koyré ([1939] 1978) attributes the occurrence of this double error to the reigning 'thinking cap' of impetus physics. The same type of explanation can be applied to the erroneous orbit calculation. Both Le Verrier and Adams used the Titius-Bode Law in order to reduce the number of variables, as this Law at least fixed the average distance to the Sun of the 'new' planet. The Titius-Bode Law approximately states that each planet is twice as far from the Sun as the one before but this only gives a rough estimation of the position of the planets and simply fails with Neptune. 
Figure 10.1 The observed orbit of Neptune compared with the calculated orbit of Neptune, as drawn by Pannekoek

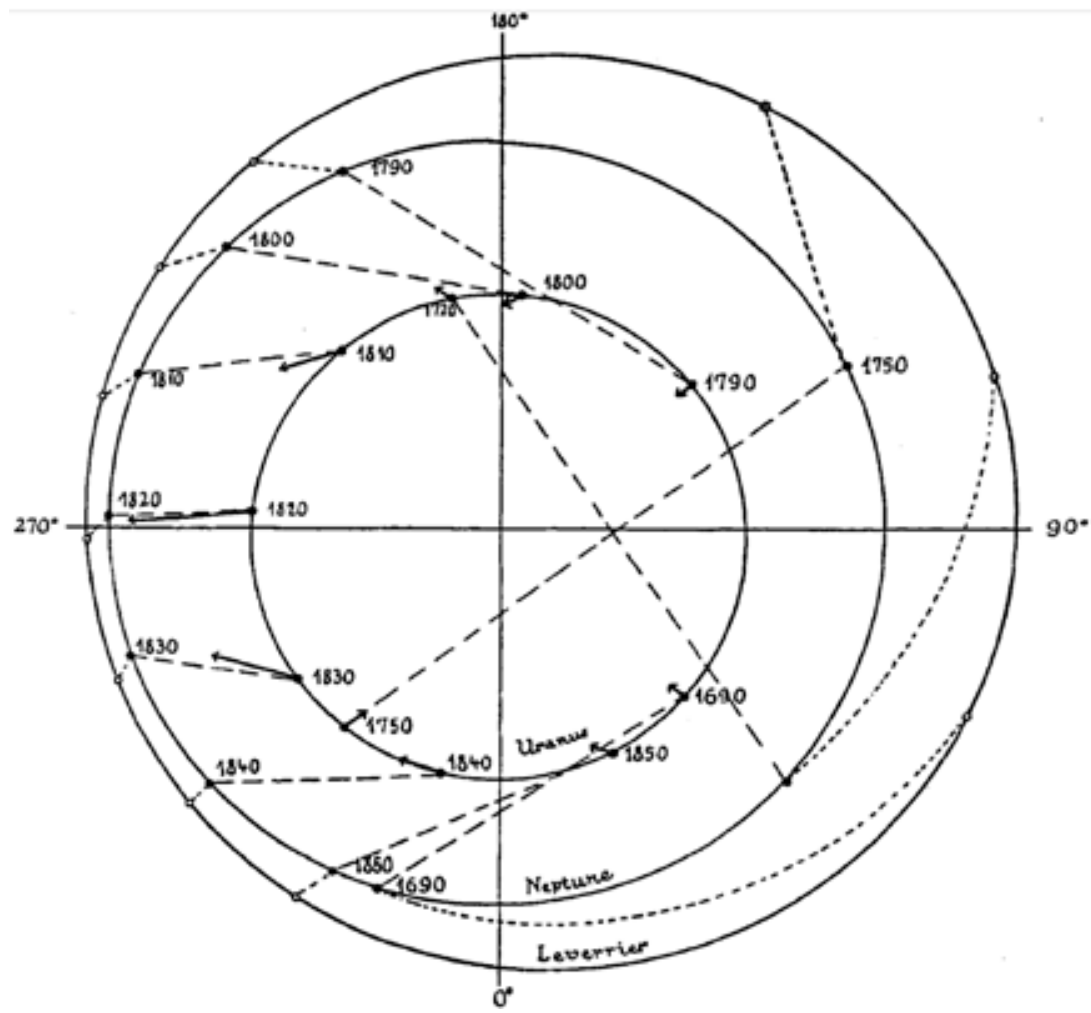

Source: Anton Pannekoek, De groei van ons wereldbeeld (Amsterdam: Wereldbibliotheek, 1951)

hence in that climate there was much more room for critical discourse. A hypothesis could be falsified without directly undermining the whole authority of science. Pannekoek therefore concludes: 'it appears clearly that not science itself but its social function ruled the attitude of scientists in Europe.'. When a prediction is falsified, this is a step forward for science but (in this case) a step backward for the use of science in social struggle. The implication is that, when all social struggles are behind us, free thinking and a maximum of critical discourse is possible. Hence in a society free of social classes there will be no obstructions to 'science itself'. ${ }^{2}$

11 Pannekoek 1953, 136.

12 As John G. Hubbell and Robert W. Smith have shown (1992), Pannekoek's account of the American part of the story has been sketchy and narrow. There were more scientists involved 
This puts the earlier discussed 'England had a better social structure than France' evaluation in perspective. England was far from perfect either, because it was still plagued with social hindrances to scientific pursuit. The distinction that Pannekoek draws between Europe and the United States is the key to understanding how social factors play a role in his explanatory framework. Social factors can enhance and temper scientific development, but they never touch the heart of science. There is an autonomous realm in which scientific development, marked by imagination, hard work and openness to critical discourse, can flourish, if freed from unwelcome social forces. This viewpoint is important to keep in mind as it crucially differs from the SSK approach, as I will demonstrate in the next section.

\section{References to Pannekoek in SSK}

The first two references to Pannekoek's paper on Neptune by SSK scholars focus on the second part of the story, because here two different methods of accounting for the data were possible and it was not directly apparent at first which one of them was correct. Both Barry Barnes and Steven Shapin argue that social factors forced a decision here. Thus Barnes writes about Pannekoek: 'What is interesting is his explanatory strategy. He perceives that at least two methods of accounting were possible, and he explains their association with two distinct contexts by references to goals and interests. Many sociologists would recognize this as a sound procedure'. ${ }^{13}$ According to Barnes, the Europeans were busy with ideological struggles in which science played an important role and the Americans were busy with demonstrating technical competence. The data could not decide between the two interpretations: 'If we are capable of recognizing that the data do

in the orbit calculations than just Walker and Peirce and the discovery of Neptune also received considerable popular interest. Hubbell and Smith argue that the American response to the discovery has to be understood as typical with respect to the relationship between American and European science. The Americans, and especially the so-called Lazzaroni group, were involved in raising the standards of scientific education and research in their country, and in this context exposing 'European arrogance' was very much welcome and actively promoted as such. Thus, the Americans too protected a national interest and used competition with other countries to further the case of science in their own country. Still, one could maintain that openness to critical discourse was what made American science at the time stronger than European science, as Pannekoek had argued. In any case, as I have already said above, the aim of this paper is not to correct Pannekoek's interpretations but rather to correct the way in which these interpretations were portrayed and used by SSK scholars three decades later.

13 Barnes 1982, 98. 
not settle matters in favor of either the opposed accounts by the scientists, then we should be able to recognize also that any interpretation we prefer will have no special status in relation to that "data". Our preferences will be a matter of how we are, more than how reality is'. ${ }^{14}$ Indeed, if this would be the case, the SSK view - which places the human element, or 'the social', at science's core - would follow. However, the uncertainty about the data only lasted for a very short period of time as the Americans quickly demonstrated that both calculations could account for the data observed in the period 1800-1850, but only theirs for data observed before and after that period. As a final decision over the correct orbit fell only after the Americans had shown this, there certainly was a sense in which the data settled matters.

Therefore, it is also hard to follow Shapin's conclusion: 'if Pannekoek is right, one of the most fundamental acts of cognitive judgement (are natural objects the same or not the same?) was in this case structured by interests in the professional status and social standing of the scientific community'.15 Again this explanation can only work when we consider a very small time frame and can certainly not be attributed to Pannekoek. With respect to the interest in professional status of Walker and Peirce, we can ask whether they were really chiefly busy with demonstrating 'technical competence'. According to Pannekoek, they were busy furthering the cause of science. In his view getting at the truth was the sole purpose of the American investigations. Reading Barnes and Shapin, it is as if the two scientific communities were epistemically equal. This does not square with Pannekoek's paper, because such a reading completely neglects his point that with less social impediments we get better science and hence that in the 1850 s the climate for science was better in the United States compared to Europe.

How can this selective reading of Pannekoek by both Barnes and Shapin be explained? I believe the answer lies in SSK's attempts to obtain a respectable place within science studies. After all, the strong programme is quite radical and may have been hard to swallow, even for those willing to grant an important role to social factors in determining the course of science. Barnes's book has the clear purpose of positioning the SSK approach with respect to other approaches, such as Kuhn's model of alternating paradigms and Garfinkel's ethnomethodology. At the same time, his aim was to demonstrate the viability of the SSK approach and 'allies' were welcome to serve

14 Barnes 1982, 96.

15 Shapin 1982, 175. Shapin refers to Barnes and it appears that he relied on Barnes' reading of Pannekoek's paper. To be fair, he also indicates that much more research is needed to establish the correct interpretation of the episode. 
this purpose. Showing that central ideas of SSK already featured in earlier historical papers made the approach less out of bounds and hence more credible. This rhetorical strategy possibly led to the crude presentation of Pannekoek's argument. ${ }^{16}$

Simon Schaffer also wrote a paper with clear programmatic overtones in 1985. His citation of Pannekoek is even more curious than the ones by Barnes and Shapin. Schaffer does not even refer to these earlier published papers but only directly to Pannekoek. He focuses exclusively on the first part of the story, which he represents in an odd way. According to Schaffer, completely different research programmes were pursued in France and Britain, both based on different 'techniques of observation'. We should therefore not speak of a multiple discovery of Neptune but of two distinct discoveries, both pertaining to the respective research programmes. ${ }^{17} \mathrm{This}$ reading of the first part of the episode strikes me as nonsensical. Le Verrier and Adams together received honour for the discovery of Neptune by the Royal Astronomical Society in 1848. Before that, French and English scientists were well aware of each other's work and corresponded through letters. ${ }^{18}$ What, then, were these different 'techniques of observation' causing a split in distinct research programmes? There is no hint to such differences in Pannekoek's paper at all. I cannot find a serious argument against the logical conclusion that on both sides of the Channel roughly the same methods of calculation and observation were used.

In my view, Schaffer's citation of Pannekoek exemplifies one of the main weaknesses of SSK, which is to create strong oppositions between conflicting parties. This is done to leave no room to settle the conflict by argument or by experimental data. Closure of scientific controversies can then only be explained with reference to social factors, as these are the only tiebreakers left. What makes Schaffer's application of this mode of explanation to the first part of the story odd is the fact that there was no epistemic conflict at all. At least in the second part of the story there was such as conflict. In the first part of Pannekoek's paper (1953), competition relates only to gaining priority for the discovery. Again, if Schaffer wants to maintain that there was a major epistemic conflict between Le Verrier and Adams, he cannot rely on Pannekoek, but strangely enough he does.

16 Various papers in Velody and Williams 1998 address SSK's rhetorical strategies. Contributions to Meister et al. 2006 investigate the 'political' strategies of SSK proponents to obtain a respectable place in science studies. See also Richards and Ashmore 1996.

17 Schaffer 1986.

18 For their correspondence, see Smith 1989. 
With David Bloor, in 2004, we are back on track with a focus on the second part of the story where the Americans join in. He reproduces the interest theory already proposed by Barnes and Shapin in the early 1980s. Thus, Bloor writes: 'Wittgenstein was right; sameness is problematic, even when we are dealing with huge pieces of matter like planets'. ${ }^{19} \mathrm{He}$ argues that astronomers in Europe and the USA pursued different interests and this led to different predictions and discoveries. If this reading of the episode can be maintained at all, and this is in my view highly doubtful, it can surely not be attributed to Pannekoek (which is what is at stake here).

Social factors play an important role in Pannekoek's account of the discovery of Neptune and the estimation of its orbit. His mode of explanation can, however, not be squared with SSK. SSK scholars take the impact of social factors a major step further and let it touch the heart of science, that is, social factors directly affect our epistemological commitments. This major step, however, cannot be found in Pannekoek's paper. Yet, he is cited as if this can be done. In the papers discussed here by Barnes, Shapin, and Schaffer, we explained this 'rich interpretation' as a result of rhetorical strategy with the purpose of trying to make the SSK approach salonfähig. Bloor's contribution to the Handbook of Epistemology (2004) is merely a repetition of earlier work by Barnes and Shapin. This contribution shows that SSK has indeed become socially accepted, and also makes Pannekoek's paper an important point of reference in science studies. These feats have been achieved at the cost of misrepresenting Pannekoek's perspective on the efficacy of social factors in the history of science. Therefore, to do him full justice, I investigate with which other major approach in the sociology of knowledge Pannekoek's mode of explanation can better be aligned in the final section of this paper.

\section{Pannekoek and Other Sociologists: Marx, Elias, and Merton}

Perhaps the most natural place to look for likeminded souls is among Marxist historians of science. After all, Pannekoek's paper was published in a special issue of Centaurus devoted to Marxist historiography to which almost all leading Marxist historians of science of the day contributed. As sociologist Norbert Elias once contended, we owe the perspective of a strong connection between human psyche and social structure to Marx and the Marxists. ${ }^{20}$ 
'Human psyche' can be broadly conceived to include science. Notwithstanding the practical work that goes into scientific research, gaining scientific knowledge is foremost a mental activity. For a classical Marxist, the psychological is always fully determined by the social. From this, it follows that scientific thinking is a function of social forces. For Pannekoek, the relation between society and human psyche was an important theme, but following Joseph Dietzgen's Das Wesen der menschlichen Kopfarbeit (1869), he defended the unorthodox position that mental change could be the cause of social change. In other words, consciousness could determine (social) being. ${ }^{21}$ In this respect, Pannekoek differed from other Marxist historians such as Boris Hessen or J.D. Bernal, who were inclined to follow the traditional idea that culture and mental life formed a superstructure on the basic socioeconomic premises.

Pannekoek opted for the less rigid interpretation of this relation because he saw in science an important driving force of social change. We have seen a clear example of this in the first part of the discovery of Neptune story. According to Pannekoek, modern science served as an important weapon for the bourgeoisie in France in the 1840s. The idea that science has the capacity to refute untenable authority (including social and political power) gives an important reason for Marxists to be interested in studying the history of science. History can show how science helped to liberate us from the rule of superstition, church, nobility, absolutism, etc. At least this led Pannekoek to another adjustment of orthodox Marxism as he recognized a positive force in the rise of the bourgeoisie as part of the whole process of the liberation of humankind. While the bourgeoisie oppressed the working class during the twentieth century, and hence needed to be defeated, the bourgeoisie was actually very effective in breaking traditional power structures during the nineteenth century. ${ }^{22}$

The general idea, to consider all mental phenomena in relation to social structures, could thus be interpreted in multiple ways. The lack of unanimity among Marxist historians of science was actually one of the reasons why Léon Rosenfeld took the initiative for a themed issue of Centaurus in 1953. It was his hope that discussions surrounding this project would lead to consensus on the matter how to conceive of the relation between science and society. ${ }^{23}$ This led to interesting contributions, which addressed a wide variety of topics, such as the relation between internal and external factors,

22 This point of view of the bourgeoisie as a temporary beneficial force led to a bitter dispute between Pannekoek and Lenin. See Pannekoek [1938] 1973.

23 Jacobsen 2008. 
the relation between the individual and society, and the proper interpretation of the succession of scientific theories.

This set of papers could have been the start of fruitful discussions on these topics. The example of Pannekoek shows that not all Marxists were inflexible dogmatists. It is very well conceivable that reference to 'Marx' would drop out entirely with increasing sophistication of discussions on the role of social factors in science. ${ }^{24}$ The message of Marxist historians, however, was badly received in the Cold War climate of the 1950s. First of all, this climate was hostile to Marxism for obvious political reasons. Secondly, intellectual historians for the most part continued to ignore the effect of social and economic circumstances on science. It did not help that 'externalism' came to be associated with Marxism. It also did not help that instead of having an open critical discourse, Marxist historians tended to fight over disagreements in a rather harsh way. In the development of thinking about science and exploring approaches to the past, we thus find something of a break-off. In a sense, SSK has picked up the trail of earlier Marxists historians of science because in SSK, social factors gain central importance again. ${ }^{25}$ From this perspective, their positive reception of Pannekoek's account of the discovery of Neptune is not surprising. The problem, however, is that Pannekoek can be aligned neither to the epistemological relativism of SSK, nor to the unilateral determinism of orthodox Marxism. Pannekoek's thought better fits with contemporary modernist sociologists such as Norbert Elias and Robert K. Merton.

Links between Elias and Pannekoek have been explored by others. ${ }^{26}$ There are indeed many similarities between the two. In both we find the connection between the social and psychological realms of human existence, including the notion that this connection is reciprocal. Both tend to study short-term events in the context of long-term processes. With respect to the latter, they have both granted an important role to the theory of evolution. In the development of science, they have also both called for attention to the study of competition between countries. ${ }^{27}$

Elias, however, following Karl Mannheim, has taken this notion of competition very far in his sociology of knowledge: 'The whole figuration

24 For example, Merton (1938) acknowledged his indebtedness to Hessen for thinking in terms of external factors, but at the same time distancing himself from Hessen's materialism.

25 For an example, see Schaffer 1984, in which he calls attention to the contributions of Hessen to the history and sociology of science. A more recent attempt at rehabilitation of Hessen can be found in Freudenthal 2005.

26 Westbroek 2012.

27 Elias 2009; see also Burke 2012. 
is animated by a continuous competitive struggle for preservation, avoidance of loss or rise of status and power chances. There is also competition for economic resources. ${ }^{28}$ It appears that this would go too far for Pannekoek. In his account of the discovery of Neptune, the struggle to be the first to claim the discovery does not occupy central stage. Pannekoek's main concern is the role science plays in society and how to improve social structure, in order for scientific research to optimally blossom. In this optimal picture, competition is not at the heart of science but cooperation is. It is not without reason that Pannekoek praises Adams's modesty as an important scholarly virtue and that he stresses the good relations between Le Verrier and Adams after the priority dispute was over.

We can see something similar in Pannekoek's evaluation of Darwinism, when applied to the study of the evolution of human societies. Where Elias was inclined to take the analogy of selection and survival of the fittest very far, Pannekoek clearly saw limits to the analogy. ${ }^{29}$ Again, he makes the point that Darwinism had been a useful weapon for the bourgeoisie in the nineteenth century to use against the 'feudal classes'. Yet, in the twentieth century the bourgeoisie could also use the theory against the proletariat in order to maintain the correctness of capitalism. In drawing an analogy between capitalist competition and the fight for survival in the animal kingdom, the bourgeoisie could justify the inequalities in wealth and power in twentieth-century Western societies. With reference to Darwin, the bourgeoisie could even present their coming out on top as a law of nature. Darwinism could be seen as complementary to Marxism in stressing continuous evolution towards improvement, but it also failed to set a good example, because it underpinned social inequality whereas socialism strives for equal access to wealth and power for everyone.

So, for Pannekoek, not all Darwinian principles could be applied to human society. On the one hand, man is a social animal and only full participation of all members of the group would make the group strongest. On the other hand, the analogy with nature breaks down when we consider the speed of change in human societies. While evolution works slowly, society changes at a rapid pace and this means that it qualitatively differs from nature. Pannekoek stressed that cultural innovation such as tools, techniques, and language acted as social cement. In order to improve living conditions, it was essential to recognize this profoundly social aspect of human culture..$^{30}$ 
Notwithstanding the many points of overlap, Pannekoek's thought differed from Elias in crucial respects. With Robert K. Merton, another prominent early sociologist of knowledge, we do not find such discrepancies. To Merton we owe a number of sociological concepts, such as 'role model', 'self-fulfilling prophecy', and 'unintended consequences', which have become so ubiquitous, that we often do not even realize he invented them. With respect to the study of science, Merton was a pioneer in the discussion about the relation between internal factors and external factors. ${ }^{31} \mathrm{He}$ thought that socio-cultural circumstances influence the course of science to a considerable degree. However, he also thought that these external factors could never touch the real heart of science. The exact shape of this internal realm differed of course from field of study to field of study, but the institution of science as a whole could be characterized as being governed by a set of invariable norms, namely: communalism, universality, disinterestedness, and organized scepticism. Good science (or real science) is marked by cooperating scientists, who are after the truth without other agendas (note how this contrasts with SSK's interest theory) and with an open mind to criticism of others (note how this corresponds to Pannekoek's evaluation of the science climate in the United States in the 1850s).

Still, the direction and pace of research could be determined by external factors. Merton's famous example comes from a comparison he made between science in protestant countries and science in catholic countries. ${ }^{32}$ Merton argued that Protestantism exhibited a set of dominant values, such as ascetism, self-reliance, ethic of hard work, discipline, etc., that created a beneficial climate for scientific pursuit. This made science move forward more rapidly in protestant countries than in catholic countries. Without the Reformation, science would thus have progressed at a much slower pace, but it would eventually have led to the same discoveries and scientific theories, most likely even in the same sequence. This Merton thesis has been met with a lot of criticism, but a discussion of the merits of the Merton thesis is not the point of this paper. ${ }^{33}$ Here, it is enough to see similarities between Merton's thesis and Pannekoek's account of the discovery of Neptune. Pannekoek argues that the French proceeded at a quicker pace than the English for social reasons, but eventually observations in England would lead to a very similar match with the calculated orbit that was already present.

31 A collection of Merton's most important papers in the sociology of knowledge can be found in Merton 1973.

32 Merton 1938.

33 Such a discussion can be found in Shapin 1988. 
That Pannekoek recognized a realm of pure science can also be inferred from remarks he makes in his two books on the history of astronomy. In $D e$ groeivan ons wereldbeeld he writes, for example: 'While the other sciences celebrate their triumph in the complete transformation of the material world, astronomy has become an adventure of the mind, a piece of pure culture. Thus, her history remains now the same as in the past: a part of humanity's cultural history'. ${ }^{34}$ From this, we can clearly infer that without practical applications, there is a realm of pure science, here called 'pure culture'. Clearly, the term 'pure culture' is used as bearing no relation to social (or external) factors.

Dick Pels once made a distinction between two main traditions in sociology of knowledge. ${ }^{35}$ On the one hand, there is the Mannheim-Merton tradition in which external factors matter, but there is also a special internal realm of science, which safeguards an epistemological realism. On the other hand, there is the Wittgenstein-Kuhn tradition, to which SSK also belongs. In this tradition, an internal realm of science, marking a continuous development of the scientific enterprise, is not recognized, which leads to a high degree of epistemological relativism. Elias can be placed somewhere in the middle with his stress on competition and Darwinism..$^{36}$ As Pannekoek differs exactly on these points from Elias, it draws him towards the Mannheim-Merton tradition. Orthodox Marxists may also be part of this tradition, but it is especially interesting for our purposes that Merton, despite complimenting Hessen for drawing attention to the role of external factors in science studies, distanced himself from Hessen because he reduced all explanation to economic forces. ${ }^{37}$ Just like Pannekoek, Merton thought such a 'vulgar materialistic' scheme of explanation was too unidirectional.

For a number of reasons, then, I believe Pannekoek's account of the discovery of Neptune accords with Merton's sociology of institutions. Apparently Pannekoek was unaware of this because we find no references to Merton, neither in the 1953 paper nor in De groei van ons wereldbeeld. Merton, on the other hand, devoted a paper to priority disputes in which he even mentions the one between Le Verrier and Adams. Although it was published after Pannekoek's paper, no reference to Pannekoek can be found in Merton's paper. Merton's conclusion there reiterates the key elements of his sociology of knowledge: 
The pursuit of science is culturally defined as being primarily a disinterested search for truth and only secondarily, a means of earning a livelihood. In line with the value-emphasis, rewards are to be meted out in accord with the measure of accomplishment. When the institution operates effectively, the augmenting of knowledge and the augmenting of personal fame go hand in hand; the institutional goal and the personal reward are tied together. But these institutional values have the defects of their qualities. The institution can get partly out of control, as the emphasis upon originality and its recognition is stepped up. $3^{8}$

For SSK scholars, getting 'out of control' can just be part of the game of science. For Merton, and also for Pannekoek, it is the point where we start to transgress the boundaries of science.

\section{Conclusion}

In this paper, I have indicated how and why Pannekoek's account of the discovery of Neptune has been hailed as a pioneer of the radical SSK approach to the study of science. However, Pannekoek can only be seen as a pioneer of the strong programme if crucial aspects of his account are skipped over. I have shown that this has happened and have suggested that this has occurred mainly for rhetorical reasons. As these are easily forgotten, especially as late as 2004, when Pannekoek's paper found its way into a handbook of epistemology, the present paper provides a necessary correction on the now apparently state-of-the-art reading of Pannekoek's interpretation of the history of science.

Pannekoek can still be seen as a pioneer when we consider that in his time historians of science paid almost no attention to the social structure of countries as an important causal factor in past priority disputes. Adding the dimension of external factors to the story was thus an innovative step towards more complex accounts of achievements of scientific discoveries. While Marxist historians of science, especially Hessen, can be credited for introducing external factors to the study of science, Pannekoek, despite being a Marxist, cannot be aligned with those historians either. He developed his own anomalous version of Marxism, which was less materialistic than orthodox versions. In Pannekoek's version, room was left for the mental to act causally upon the social and this formed an important building block of 
his argumentation in his 1953 paper on the discovery of Neptune. Comparing his interpretation of this episode in the history of science with other sociologists of knowledge, we found that it accords best with Merton's sociology of institutions. While some have claimed that since the advent of SSK, explaining science with a model that is based on (some interpretation of) the distinction between internal and external factors has become obsolete, ${ }^{39}$ others have recently started to return from SSK's radicalism because of the negative effects of embracing an omnibus epistemological relativism. One of SSK's early proponents, Harry Collins, has for example called for a return to Mertonian values, which he now calls 'elective modernism'. ${ }^{40}$ Should this revaluation of Merton find more support in the future, Pannekoek can again be hailed as a pioneer, as his 1953 paper can be read as an early exemplification of the Mertonian approach to the study of past science. Should this identification occur, this paper demonstrates that it would at least be on justificatory grounds.

\section{Bibliography}

Barnes, Barry. 1982. T.S. Kuhn and Social Science. New York: Columbia University Press.

Bloor, David. 1976. Knowledge and Social Imagery. London: Routledge \& Kegan Paul. -. 2004. 'Sociology of Scientific Knowledge'. In Handbook of Epistemology, ed. by Ilkka Niiniluoto, Matti Sintonen, and Jan Woleński. Dordrecht: Kluwer, 919-962.

Burke, Peter. 2012. 'Norbert Elias and the Social History of Knowledge'. Human Figurations 1(1). http://hdl.handle.net/2027/spo.11217607.0001.102 (accessed 16 September 2016).

Collins, Harry M. 2010. Gravity's Ghost: Scientific Discovery in the Twenty-First Century. Chicago, IL: University of Chicago Press.

Collins, Harry M., and Robert J. Evans. 2002. 'The Third Wave of Science Studies: Studies of Expertise and Experience'. Social Studies of Science 32(2): 235-296.

Elias, Norbert. 2009. Essays I: On the Sociology of Knowledge and the Sciences. Ed. by Richard Kilminster and Stephen Mennell. Collected Works of Norbert Elias 14. Dublin: University College Dublin Press.

Freudenthal, Gideon. 2005. 'The Hessen-Grossman Thesis: An Attempt at Rehabilitation'. Perspectives on Science 13(2): 166-193.

39 Shapin (1992).

40 Collins 2010. For his ideas to move beyond SSK and follow a third wave of science studies dating back as far as 2002, see Collins and Evans 2002. 
Golinski, Jan. 2005. Making Natural Knowledge: Constructivism and the History of Science. Chicago, IL: University of Chicago Press.

Hubbell, John G., and Robert W. Smith. 1992. 'Neptune in America: Negotiating a Discovery'. Journal for the History of Astronomy 23(4): 261-291.

Jacobsen, Anja Skaar. 2008. 'The Complementarity Between the Collective and the Individual: Rosenfeld and Cold War History of Science'. Minerva 46(2): 195-214. Jardine, Nicholas. 2001. 'Sammlung, Wissenschaft, Kulturgeschichte'. In Sammeln als Wissen: das Sammeln und seine wissenschaftsgeschichtliche Bedeutung, ed. by Anke te Heesen and Emma C. Spary. Göttingen: Wallstein.

Koyré, Alexandre. (1939) 1978. Galileo Studies. Hassocks, UK: Harvester Press.

McAllister, James W. 2015. 'Rhetoric of Effortlessness in Science'. Perspectives on Science 24(2): 145-166.

Meister, Martin, Ingo Schulz-Schaeffer, Stefan Böschen, Jochen Glässer, and Jörg Strübing, eds. 2006. 'What Comes after Constructivism in Science and Technology Studies'. Science, Technology \& Innovation Studies, Special issue 1.

Merton, Robert K. 1938. 'Science, Technology and Society in Seventeenth Century England'. Osiris 4: 36o-632.

- 1957. 'Priorities in Scientific Discovery: A Chapter in the Sociology of Science'. American Sociological Review 22(6): 635-659.

-. 1973. The Sociology of Science: Theoretical and Empirical Investigations. Chicago, IL: University of Chicago Press.

Pannekoek, Anton. 1909. Marxismus und Darwinismus. Ein Vortrag. Leipzig: Leipziger Buchdruckerei.

-.1913. 'Dietzgens Werk'. Die Neue Zeit 31(28): 37-47.

-.1951. De groei van ons wereldbeeld. Amsterdam: Wereldbibliotheek.

-. 1953. 'The Discovery of Neptune'. Centaurus 3(1): 126-137.

-.1961. A History of Astronomy. London: George Allen and Unwin.

-. (1938) 1973. Lenin als filosoof. Een kritische beschouwing over de filosofische grondslagen van het leninisme. Amsterdam: De Vlam.

Pels, Dick. 1996. 'Karl Mannheim and the Sociology of Scientific Knowledge: Toward a New Agenda'. Sociological Theory 14(1): 30-48.

Richards, Evelleen, and Malcolm Ashmore. 1996. 'More Sauce Please! The Politics of SSK: Neutrality, Commitment and Beyond'. Social Studies of Science 26(2):219-228. Schaffer, Simon. 1984. 'Newton at the Crossroads'. Radical Philosophy 37: 23-38.

- 1986. 'Scientific Discoveries and the End of Natural Philosophy'. Social Studies of Science 16(3): 387-420.

Shapin, Steven. 1982. 'History of Science and Its Sociological Reconstructions'. History of Science 20(3): 157-211.

—. 1988. 'Understanding the Merton Thesis'. Isis 79(4): 594-605. 
—. 1992. 'Discipline and Bounding: The History and Sociology of Science as Seen through the Externalism-Internalism Debate'. History of Science 3o(4): 333-369.

Sheehan, William, and Steven Thurber. 2007. 'John Couch Adams's Asperger Syndrome and the British Non-Discovery of Neptune'. Notes and Records of the Royal Society 61(3): 285-299.

Smith, Robert W. 1989. 'The Cambridge Network in Action: The Discovery of Neptune'. Isis 8o(3): 395-422.

Velody, Irving, and Robin Williams, eds. 1998. The Politics of Constructionism. London: Sage.

Westbroek, Peter. 2012. 'Civilizing Earth'. Human Figurations 1(1). http://hdl.handle. net/2027/spo.11217607.0001.108 (accessed 3 February 2016).

\section{About the Author}

Bart Karstens is Postdoctoral Research Fellow at the Vrije Universiteit Amsterdam and the Vossius Center of the University of Amsterdam. In 2015, he defended his PhD thesis 'Pluralism within Parameters', on the conceptualization of error in historiography of science, at Leiden University. He is interested in discipline formation, interaction between disciplines, assessments of past science, historical epistemology of 'structure' and 'structuralism', comparativism, digital humanities, and digital culture. 
